\title{
Radial Aplasia-Thrombocytopenia Syndrome
}

National Cancer Institute

\section{Source}

National Cancer Institute. Radial Aplasia-Thrombocytopenia Syndrome. NCI Thesaurus. Code $C 99038$.

A rare syndrome characterized by the presence of thrombocytopenia associated with bilateral absence of the radius bone. 